\title{
What is the Safe Training to Educate the Laparoscopic Cholecystectomy for Surgical Residents in Early Learning Curve?
}

\author{
Yun Kyung Jung, M.D. ${ }^{1}$, Yong Jin Kwon, M.D. ${ }^{2}$, Dongho Choi, M.D., Ph.D. ${ }^{1}$, Kyeong Geun Lee, M.D., Ph.D. ${ }^{1}$ \\ Department of Surgery, ${ }^{1}$ Hanyang University College of Medicine, ${ }^{2}$ Hallym University College of Medicine, Kangnam Sacred Heart Hospital, Seoul, Korea
}

Purpose: This study was conducted to investigate the safety of laparoscopic cholecystectomy (LC) performed by surgical residents.

Methods: We reviewed the records of patients who underwent LC for chronic cholecystitis and gallbladder polyps between February 2010 and July 2012. All diagnoses were confirmed by biopsy. All procedures performed by surgical residents were conducted under the close supervision of an experienced laparoscopic surgeon. A standard four-port method was used, and we achieved the critical view of safety in almost all patients.

Results: Of 219 LC procedures, 136 were performed by an experienced laparoscopic surgeon, and 83 by surgical residents. There was no significant difference in postoperative hospital stay (1.1 vs. 1.2 days, $p=0.337$ ) or complication rates $(3.7 \%$ vs. $2.4 \%, p=0.712)$ between groups. However, the patients operated on by surgical residents had significantly longer operation times (40.7 vs. $63.7 \mathrm{~min}, p<0.05)$.

Conclusion: LC performed by inexperienced surgical residents under the supervision of an experienced surgeon is safe and feasible for chronic cholecystitis and gallbladder polyps. Major bile duct injury is strongly correlated with having performed fewer than $20 \mathrm{LC}$ procedures, so surgical residents must secure the critical view of safety, and the supervising surgeon must confirm it before the cystic duct and cystic artery are ligated.

Keywords: Laparoscopic cholecystectomy, Biliary, Training, Surgical resident, Complication
Received April 18, 2016

Revised May 31, 2016

Accepted June 3, 2016

Corresponding author

Kyeong Geun Lee

Department of Surgery, Hanyang

University College of Medicine,

17 Haengdang-dong, Seongdong-

gu, Seoul 04763, Korea

Tel: $+82-2-2290-8448$

Fax: +82-2-2281-0224

E-mail: hepafel@hanyang.ac.kr
This is an Open Access article distributed under the terms of the Creative Commons Attribution Non-Commercial License (http:// creativecommons.org/licenses/by-nc/4.0/) which permits unrestricted non-commercial use, distribution, and reproduction in any medium, provided the original work is properly cited.
Copyright @ 2016 The Journal of Minimally Invasive Surgery. All rights reserved.

\section{INTRODUCTION}

Laparoscopic cholecystectomy (LC) is the most frequently performed operation on the digestive tract, and it is essential for surgical residents to acquire the necessary skills to perform the procedure safely. However, inexperienced surgeons are reluctant to perform it because of the risk of bile duct injury.

The rate of major bile duct injury is higher during LC than during open cholecystectomy $(0.4 \sim 0.7 \% \text { vs } 0.2 \%)^{1}$ and is strongly correlated with surgical inexperience and having per- formed fewer than 20 LC procedures. Michael et al. ${ }^{2}$ reported that $90 \%$ of biliary injuries occurred during the first $30 \mathrm{LC}$ procedures. Visual misperception is the most common cause (97\%) of iatrogenic bile duct injuries, while lack of technical skill or knowledge accounts for only $3 \% .^{3}$ The most common injury is complete transection of the common bile duct. For this reason, adequate training of surgical residents is crucial.

The aim of our study was to investigate the safety of laparoscopic cholecystectomy performed by surgical residents, and to discuss the most appropriate methods of training. 


\section{MATERIALS AND METHODS}

We reviewed retrospectively the records of 219 consecutive patients who underwent LC for chronic cholecystitis and gallbladder polyps between February 2010 and July 2012, in Hanyang University Seoul Hospital. All 219 LC procedures used a four-port technique; we excluded all cases of single- or threeport LC. The residents did not operate on patients with acute cholecystitis or gallbladder empyema because such cases tend to be hyperemic and edematous. The supervisors selected the cases appropriate for the surgical residents, with cases with severe inflammation and anatomical variation on preoperative CT also being excluded. The supervisors directed the residents to operate on many cases in which an endoscopic nasobiliary drainage (ENBD) catheter had been inserted after preoperative endoscopic retrograde cholangiopancreatography (ERCP) for suspected common bile duct stones, since the catheter facilitated identification and securing of the common bile duct. The patients were divided into two groups according to the surgeons involved: 136 LCs were performed by a hepatobiliary surgeon, and 83 by 10 surgical residents (range: 1 to 19 ).

All the surgical residents were senior residents who had participated at least 50 laparoscopic appendectomies or LC procedures as operators or scopists, so that they had already developed basic laparoscopic skills. All the procedures performed by them were carried out under the close supervision and guidance of an experienced laparoscopic surgeon. The supervisors were two surgeons who performed at least $250 \mathrm{LC}$ per year. The supervisors were often observers, and sometimes scopists. The supervisor confirmed the critical view of safety (CVS) in every case, by checking the site between dissected cystic duct and gallbladder. Additional examinations including cholagiograms were not carried out since the CVSs were secured.

SPSS 17.0 software (Chicago, IL, USA) was used for statistical analysis. The chi-square and Fisher's exact tests were used for categorical variables, and Student's t-test for continuous variables. Values of $p<0.05$ were considered statistically significant.

Table 1. Comparison of pre-operative general characteristics and surgical outcomes

\begin{tabular}{|c|c|c|c|c|}
\hline \multirow{2}{*}{ Pre-operative characteristics } & \multicolumn{2}{|c|}{ Operator } & \multirow{2}{*}{ Total $(n=219)$} & \multirow{2}{*}{$p$} \\
\hline & Surgeon $(n=136)$ & Resident ( $n=83$ ) & & \\
\hline Age, years & $51.1( \pm 13.9)$ & $53.8( \pm 11.5)$ & $52.1( \pm 13.0)$ & 0.140 \\
\hline Male to female ratio & 1.3 & 0.9 & 1.2 & 0.187 \\
\hline Body mass index, $\mathrm{kg} / \mathrm{m}^{2}$ & $24.9( \pm 3.7)$ & $24.7( \pm 3.0)$ & $24.8( \pm 3.4)$ & 0.651 \\
\hline White blood count, $/ \mathrm{mm}^{3}$ & $7,199.3( \pm 2,324.2)$ & $6,955.4( \pm 2,583.0)$ & $7,110.9( \pm 2,412.3)$ & 0.471 \\
\hline Total bilirubin, mg/dL & $1.2( \pm 2.1)$ & $1.3( \pm 1.7)$ & $1.2( \pm 1.9)$ & 0.768 \\
\hline Alkaline phosphatase, U/L & $92.7( \pm 73.7)$ & $100.4( \pm 122.0)$ & $95.5( \pm 94.3)$ & 0.561 \\
\hline Aspartate aminotransferase, $\mathrm{U} / \mathrm{L}$ & $76.5( \pm 139.5)$ & $70.4( \pm 101.2)$ & $74.0( \pm 126.0)$ & 0.726 \\
\hline Alanine aminotransferase, U/L & $85.8( \pm 152.0)$ & $79.0( \pm 129.1)$ & $82.9( \pm 143.0)$ & 0.736 \\
\hline Critical view of safety, n $(\%)$ & $134(98.5)$ & 82 (98.8) & $216(98.6)$ & 1.000 \\
\hline ERCP, n $(\%)$ & $23(16.9)$ & $20(24.1)$ & $42(19.6)$ & 0.194 \\
\hline Pancreatitis, n $|\%|$ & $2(1.5)$ & $3(3.6)$ & $5(2.3)$ & 0.370 \\
\hline Diabets Mellitus, $n(\%)$ & $17(12.5)$ & $10(12.0)$ & 27 (12.3) & 0.921 \\
\hline Hypertension, n $(\%)$ & $23(16.9)$ & $18(21.7)$ & $41(18.7)$ & 0.379 \\
\hline \multirow{2}{*}{ Surgical outcomes } & \multicolumn{2}{|c|}{ Operator } & \multirow{2}{*}{ Total $(n=219)$} & \multirow{2}{*}{$p$} \\
\hline & Surgeon $(n=136)$ & Resident ( $n=83$ ) & & \\
\hline Operation time, minutes & $40.7( \pm 11.4)$ & $63.7( \pm 16.8)$ & $49.5( \pm 17.7)$ & $<0.001$ \\
\hline Post-operative stay, days & $1.1( \pm 0.4)$ & $1.2( \pm 0.6)$ & $1.1( \pm 0.5)$ & 0.337 \\
\hline Hospital stay, days & $3.6( \pm 3.0)$ & $4.1( \pm 3.4)$ & $3.8( \pm 3.1)$ & 0.182 \\
\hline Complication, n (\%) & $5(3.7)$ & $2(2.4)$ & $7(3.2)$ & 0.712 \\
\hline
\end{tabular}

ERCP $=$ endoscopic retrograde cholangiopancreatography. 


\section{RESULTS}

Of the 219 LC procedures, 136 were performed by the experienced laparoscopic surgeons, and 83 by the surgical residents. The demographic characteristics and laboratory findings were similar in the two groups. There was no significant difference in postoperative hospital stay (1.1 vs 1.2 days, $p=0.337)$ or complication rate $(3.7 \%$ vs $2.4 \%, p=0.712)$ between the patients operated on by experienced surgeons and surgical residents. However, the patients who underwent LC by the surgical residents had significantly longer operation times (40.7 vs $63.7 \mathrm{~min}, p<0.05$ ) (Table 1).

Complications occurred in 5 cases that were operated on by supervisors, and 2 cases operated on by residents. All of them were wound seroma or infections; no major complications, including bile duct injury, occurred.

There were no instances of conversion during the study period. The operator was changed during one LC performed by a surgical resident because of difficulty achieving the CVS. During two LCs performed by an experienced surgeon and one by a surgical resident the CVS could not be achieved, and the common bile duct was confirmed visually.

\section{DISCUSSION}

While LC is a basic general surgical procedure, it carries the risk of bile duct injury. Therefore, adequate training of surgical residents is essential. Archer et al. ${ }^{4}$ reported that residency training decreases the likelihood of injuring to the bile duct.

A variety of training methods have been proposed, such as training on animals ${ }^{5}$ and, in recent years, using a virtual reality simulator. ${ }^{6-8}$ In our hospital, there is no LC-specific

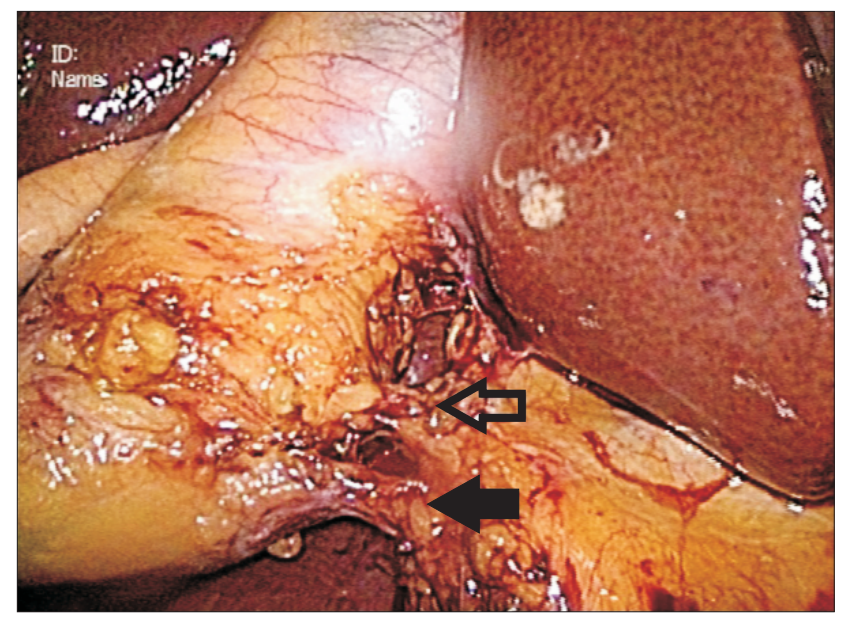

Fig. 1. Critical view of safety (filled arrow: cystic duct, empty arrow: cystic artery). training system for surgical residents. However, the LCs in our study were performed by third or fourth year residents who had carried out at least ten laparoscopic appendectomies and had participated in at least ten LC procedures as scopists.

The operation was the entire dissection of hepatocystic triangle, exposing the cystic duct and artery, the infundibulum of the gallbladder, and the junction of the gallbladder and cystic duct before division of the cystic duct and artery.

Use of the CVS technique has been advocated to prevent complete transection of the common bile duct (Fig. 1). ${ }^{9}$ During the operation a few surgical residents tried to ligate the cystic duct before CVS had been attained. They said that ligating the cystic duct which is in front of Calot's triangle would have made the operation easier. The supervisor had to warn them in each case that unconfirmed CVS could lead to ligation of the common bile duct instead of the cystic duct.

In 1924 Henri Rouviere ${ }^{10}$ identified a sulcus that has come to be used as a landmark in cholecystectomy to help identify a safe dissection line. ${ }^{11-13}$ Dissection ventral to Rouviere's sulcus has been associated with minimal incidence of common bile duct injury (Fig. 2). ${ }^{11,14}$

Way et al. ${ }^{3}$ suggested that illusions of visual perception, to which everyone is susceptible, are the primary cause of laparoscopic biliary injuries, and that laparoscopic procedures should be standardized. The surgical residents in our study performed LC by following prescribed steps. First, the dissection line was identified using Rouviere's sulcus and the falciform ligament. Using a dissector, the posterior and then the anterior side was dissected. To prevent thermal injury, Bovie use was minimized. Once the cystic duct had been identified, Calot's triangle was dissected completely. The surgical residents had to secure CVS, and the supervising surgeon had

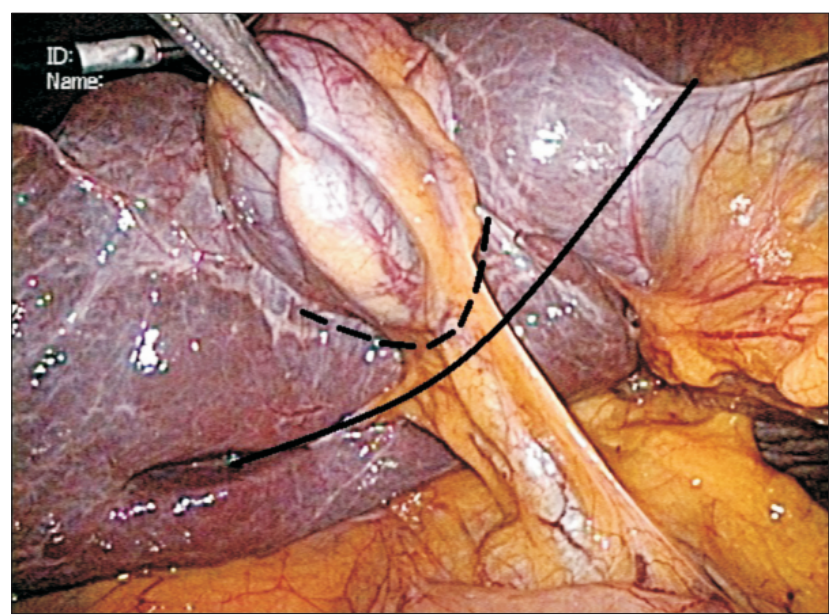

Fig. 2. Rouviere's sulcus and the dissection line Isolid line: Rouviere's sulcus plane, dotted line: dissection plane). 

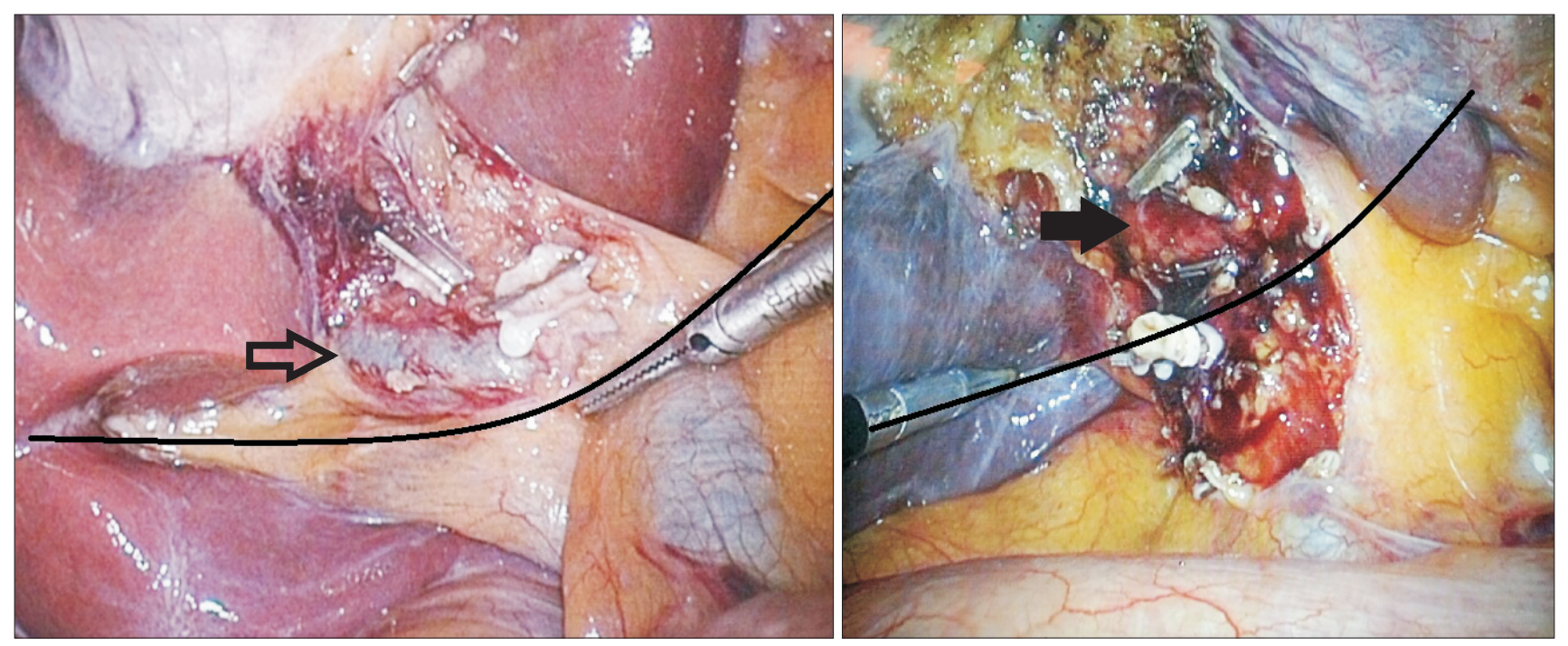

Fig. 3. Anterior branch of right hepatic duct and right hepatic artery place above Rouviere's sulcus plane Isolid line: Rouviere's sulcus plane, empty arrow: anterior branch of right duct, filled arrow: right hepatic artery).

to confirm it before ligating the cystic duct and cystic artery. After ligation, dissection was performed close to the GB. Because energy devices, such as the harmonic scalpel, may disrupt the dissection plane, they were not used.

The most important considerations in relation to operations performed by surgical residents are the following. The most important initial step is deciding on the correct dissection line. In that step, it is important to confirm Rouviere's sulcus. The second step is securing the "critical view of safety" while minimizing the use of a Bovie to dissect Calot's triangle. In this step, we should not carry out unnecessary control of bleeding. The third is deciding on the line for dissecting the hepatocystic triangle after ligation of the cystic duct and cystic artery. If we decide on the wrong dissection line, the chance of injury to the right hepatic duct, right portal vein or right hepatic artery will increase. The dissection line must be close to gallbladder because right hepatic duct or artery often place above Rouviere's sulcus (Fig. 3). When surgical residents are operating under supervision they often make the wrong decision, and it is essential that the supervisor intervene at that point.

In conclusion, laparoscopic cholecystectomy can be performed safely by supervised residents, with outcomes similar to those obtained by experienced attending surgeons. Major bile duct injury is strongly correlated with having performed fewer than 20 LC procedures, so surgical residents must achieve the "critical view of safety", and the supervising surgeon must confirm it, before the cystic duct and cystic artery are ligated.

Supervisors should help to decide on the correct dissection line and intervene to check unnecessary bleeding control using a Bovie, and they must confirm the CVS in early learning curve period.

\section{REFERENCES}

1) Krahenbuhl L, Sclabas G, Wente MN, Schafer M, Schlumpf R, Buchler MW. Incidence, risk factors, and prevention of biliary tract injuries during laparoscopic cholecystectomy in Switzerland. World J Surg 2001;25:1325-1330.

2) Moore MJ, Bennett CL. The learning curve for laparoscopic cholecystectomy. The Southern Surgeons Club. Am J Surg 1995;170: $55-59$.

3) Way LW, Stewart L, Gantert W, et al. Causes and prevention of laparoscopic bile duct injuries: analysis of 252 cases from a human factors and cognitive psychology perspective. Ann Surg 2003;237:460-469.

4) Archer SB, Brown DW, Smith CD, Branum GD, Hunter JG. Bile duct injury during laparoscopic cholecystectomy: results of a national survey. Ann Surg 2001;234:549-558; discussion 558-549.

5) Hunter JG, Sackier JM, Berci G. Training in laparoscopic cholecystectomy. Quantifying the learning curve. Surg Endosc 1994;8:28-31.

6) Schijven MP, Jakimowicz JJ, Broeders IA, Tseng LN. The Eindhoven laparoscopic cholecystectomy training course--improving operating room performance using virtual reality training: results from the first E.A.E.S. accredited virtual reality trainings curriculum. Surg Endosc 2005;19:1220-1226.

7) Grantcharov TP, Kristiansen VB, Bendix J, Bardram L, Rosenberg J, Funch-Jensen P. Randomized clinical trial of virtual reality 
simulation for laparoscopic skills training. Br J Surg 2004;91:146150.

8) Wohaibi EM, Bush RW, Earle DB, Seymour NE. Surgical resident performance on a virtual reality simulator correlates with operating room performance. J Surg Res 2010;160:67-72.

9) Strasberg SM, Hertl M, Soper NJ. An analysis of the problem of biliary injury during laparoscopic cholecystectomy. J Am Coll Surg 1995;180:101-125.

10) Rouviere H. Sur la configuration et la signification du sillon du processus caude. Bulletins et memoires de la societe anatomique de paris 1924;94:355-358.
11) Hugh TB, Kelly MD, Mekisic A. Rouviere's sulcus: a useful landmark in laparoscopic cholecystectomy. Br J Surg 1997;84:12531254.

12) Hugh TB. New strategies to prevent laparoscopic bile duct injury--surgeons can learn from pilots. Surgery 2002;132:826-835.

13) Zubair M, Habib L, Memon F, Mirza M, Khan M, Quraishy M. Rouviere's sulcus: A guide to safe dissection in laparoscopic cholecystectomy. Parkistan J Surg 2009;25:119-121.

14) Singh K, Ohri A. Anatomic landmarks: their usefulness in safe laparoscopic cholecystectomy. Surg Endosc 2006;20:1754-1758. 